

\title{
A territorialização do programa Bolsa Família na comunidade rural Sítio Carnaubal - Água Nova/RN: a voz dos beneficiários
}

The territorialisation of the Bolsa Família Program in the rural community of Sítio Carnaubal - Água Nova/RN: the beneficiaries' voice

Referência: Lima, Francisca ; Melo, Felipe ; Soares, Lady (2017). A territorialização do programa Bolsa Família na comunidade rural Sítio Carnaubal - Água Nova/RN: a voz dos beneficiários. Revista de Geografia e Ordenamento do Território (GOT), n. 12 (dezembro). Centro de Estudos de Geografia e Ordenamento do Território, p. 179-203, dx.doi.org/10.17127/got/2017.12.008

\section{RESUMO}

O presente artigo $^{1}$ realiza um estudo a respeito da pobreza rural a partir do viés da multidimensionalidade e considera o Programa Bolsa Família (PBF), criado pelo Governo Federal do Brasil, uma política pública que vem contribuindo com a minimização da pobreza e tem aumentado a possibilidade de permanência do homem no campo. Nesta perspectiva, o objetivo principal deste trabalho é analisar os impactos do PBF no contexto socioeconômico das famílias beneficiárias residentes na comunidade rural do Sítio Carnaubal no município de Água Nova, uma pequena cidade do Rio Grande do Norte (RN), estado localizado na região nordeste do Brasil. Procura-se compreender, ainda, entre outros

\footnotetext{
${ }^{1} \mathrm{O}$ presente artigo é um recorte do nosso trabalho de monografia na Especialização em Educação do Campo/Saberes da Terra pelo IFRN (LIMA; SOARES, 2015).
} 
aspectos, a territorialização das políticas públicas sociais de combate à pobreza, bem como a territorialização do PBF na comunidade em estudo, com um especial interesse em descobrir de que modo o programa é percebido pelos beneficiários residentes no território referido.

Palavras-chave: Pobreza rural. Território. Políticas públicas sociais. Programa Bolsa Família.

\section{ABSTRACT}

This paper constitutes a study on rural poverty from the perspective of multidimensionality and it considers the Bolsa Família Program (BFP), created by the federal goverment of Brazil, a public policy that has contributed to the alleviation of poverty and has also increased the possibility of permanence of men in countryside. In this way, the main objective of this work is to analyze the impact of BFP in the socioeconomic context of the beneficiary families living in the rural community of Sítio Carnaubal (Carnaubal Village) in Água Nova, a small town in Rio Grande do Norte (RN), a state located in the northeastern region of Brazil. The research aims at understanding, among other aspects, the territorialisation of public social policies to combat poverty, as well as the territorialisation of BFP in the area under study, and it is especially interested to comprehend how the program is perceived by the beneficiaries residing in the locale refered to.

Keywords: Rural poverty. Territory. Social public policy. Bolsa Família Program.

\section{Introdução}

A presente pesquisa ${ }^{2}$ surgiu da constatação de que o Programa Bolsa Família (doravante, $\mathrm{PBF}$ ) do Governo Federal é um dos principais programas de transferência de renda do Brasil. Por sua abrangência, ele chega também aos espaços rurais. Verificamos, contudo, que existem muitos trabalhos acerca do Programa territorializado no espaço urbano, ao passo que poucas são as referências a seu processo de territorialização no espaço rural. Dessa forma, na certeza de serem muitos os impactos dessa política pública no contexto de vida do homem do campo, interessou-nos analisar seus impactos a partir do recorte territorial de uma comunidade rural.

Selecionada a comunidade ${ }^{3}$, a questão problematizadora primeira para a análise foi a seguinte: de que forma o Programa Bolsa Família tem contribuído com a melhoria de vida (avaliada, neste estudo, somente com base nos aspectos sociais e econômicos) das famílias

\footnotetext{
${ }^{2}$ A maior parte do aporte teórico e da escolha metodológica utilizados neste artigo, afora algumas reflexões, segue o trabalho de Lima (2014), em que foi estudado o processo de territorialização das políticas públicas no bairro Manoel Deodato, zona urbana do município de Pau dos Ferros, município do extremo oeste do Rio Grande do Norte.

${ }^{3}$ O critério para a seleção da comunidade foi pessoal, vindo do desejo de um dos autores deste trabalho, Elizonete Lima, de compreender melhor o impacto do PBF na dinâmica social da comunidade em que vive até hoje, o Sítio Carnaubal.
} 
beneficiárias residentes na comunidade rural Sítio Carnaubal do município de Água Nova/RN? Partindo desse questionamento inicial, a pesquisa teve como objetivo principal analisar os impactos do PBF no contexto socioeconômico das famílias beneficiárias residentes na comunidade rural Sítio Carnaubal no município de Água Nova/RN, buscando compreender, ainda, entre outros pontos, a territorialização das políticas públicas sociais de combate à pobreza, bem como a territorialização do PBF na comunidade em estudo, interessando-nos entendê-lo a partir da percepção dos beneficiários residentes no Sítio Carnaubal, locus da pesquisa.

\subsection{Breve apresentação da comunidade Sítio Carnaubal}

A comunidade Sítio Carnaubal está localizada no município de Água Nova, no Rio Grande do Norte, estado situado na região Nordeste do Brasil. O município está localizado na microrregião da Serra de São Miguel e na mesorregião do Oeste Potiguar. A comunidade fica a 4 quilômetros de distância da cidade e conta com 78 famílias, totalizando 227 habitantes, dos quais 119 são mulheres e 108, homens (dados da Secretaria de Saúde do Município).

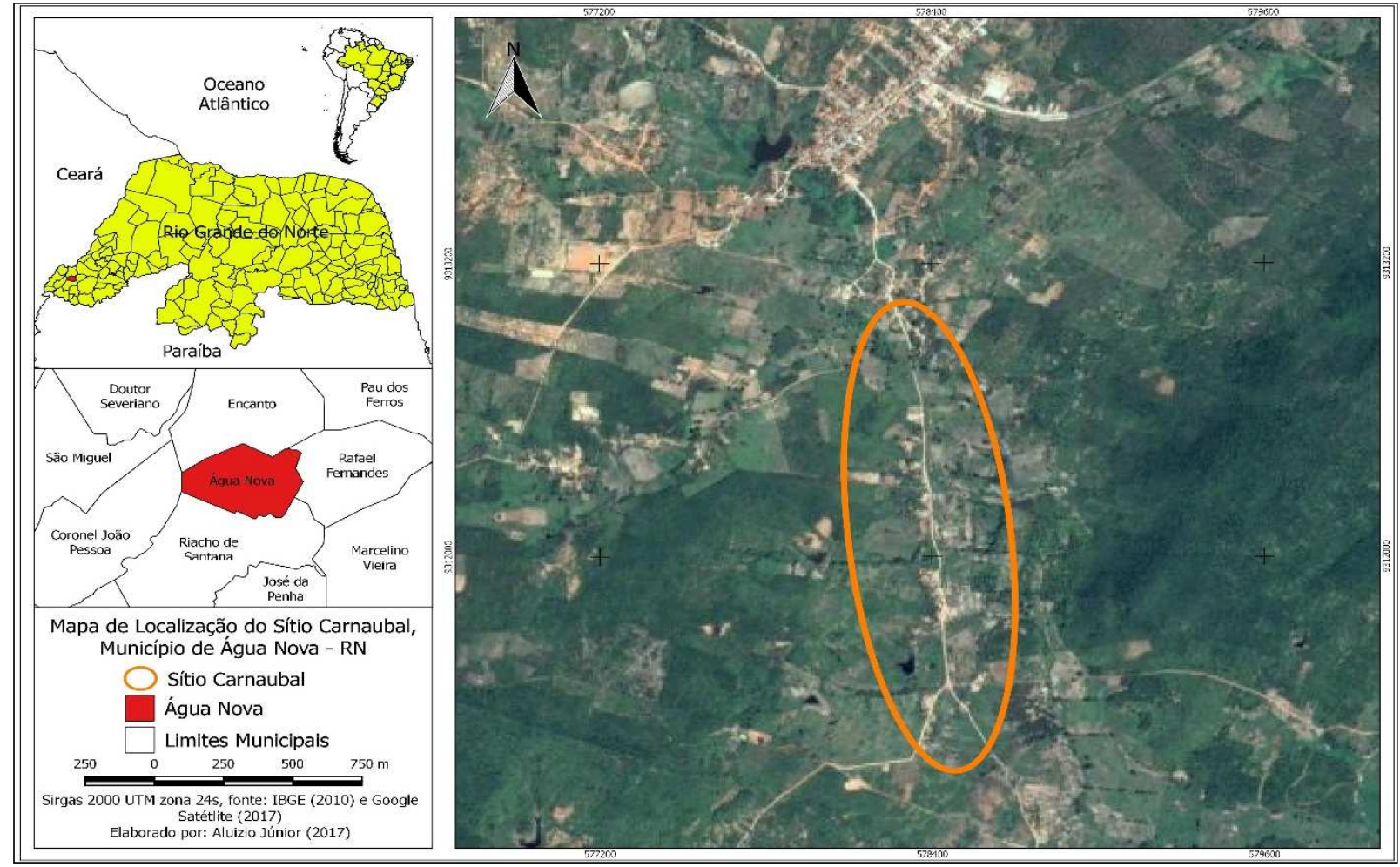

Figura 01: Mapa de localização da comunidade rural Sítio Carnaubal.

Fonte: Júnior (2017). 
A comunidade ganhou esse nome devido à grande quantidade de plantas conhecidas por carnaúbas, que existiam em abundância nessa localidade. Segundo alguns moradores mais antigos, era comum a utilização dessa planta para a produção de alimentos para os animais e também para uso no artesanato, adubação do solo e extração de cera. Assim, durante muitos anos, a comunidade sobreviveu da agricultura, com destaque para a produção de cana de açúcar, que gerava renda e trabalho local, uma vez que existiam na comunidade engenhos ativos que produziam rapaduras, garapas, mel e demais derivados da cana.

Atualmente, o uso da carnaúba é bastante escasso, havendo ainda algumas famílias que utilizam sua cera para fins domésticos, sem geração de renda, contudo; a atividade canavieira, por sua vez, foi totalmente extinta. Em decorrência disso, a sobrevivência das famílias residentes na comunidade atualmente advém de benefícios sociais, como aposentadoria rural, Benefício de Prestação Continuada (BPC), PBF e pequenas atividades agropecuárias. Estas, no entanto, veem-se fragilizadas no momento presente devido à longa estiagem pela qual está passando a região, ao que se soma a negligência do setor público. Historicamente, aliás, a seca é um dos grandes condicionantes que agrava a pobreza no Nordeste brasileiro, não apenas pelo componente climático que representa, mas, sobretudo, por sustentar, do ponto de vista do discurso e dos recursos públicos, a tão falada indústria da seca ${ }^{4}$, mecanismo que serviu para o enriquecimento das oligarquias regionais e a manutenção no poder da elite dominante.

\footnotetext{
${ }^{4}$ Para o homem do campo nordestino, muito mais grave do que as sequentes secas é a indústria que delas fazem os poderosos da região. "Em todas as secas do Nordeste surgiu este tipo de 'indústria', cuja matériaprima é a apropriação indébita dos dinheiros públicos enviados para socorrer os famintos, ou tráfico de influência em benefício dos detentores do poder ou ainda a montagem de um sistema de exploração em cima de uma população exaurida nos seus parcos recursos. É, por excelência, a 'indústria' abjeta. [...] Desde o início da política de combate às secas, quando o governo tomou as primeira providências para socorrer os flagelados do Nordeste, que os socorros públicos vêm sendo capturados pelas oligarquias municipais e estaduais e utilizados para fins eleitoreiros" (SOUZA e FILHO, 1984, p. 90).
} 


\section{Pobreza multidimensional: algumas reflexões sobre a pobreza rural e a possível permanência do homem no campo}

A fim de atingir satisfatoriamente a meta a que nos propusemos neste trabalho, faz-se importante uma discussão/reflexão acerca do fenômeno da pobreza, haja vista o referido programa ter como público alvo as famílias pobres e extremamente pobres. Além disso, como nosso recorte espacial se trata de uma comunidade rural, é preciso entender a pobreza territorializada neste espaço, desvendando em que medida o PBF pode contribuir também para a permanência do homem no campo. Mesmo não sendo esse o objetivo do programa, que beneficia igualmente os sujeitos do campo e da cidade, neste momento, pelo enfoque de nossa pesquisa, buscaremos compreender seus possíveis impactos na zona rural.

\subsection{As diversas dimensões da pobreza: a pobreza multidimensional}

Para refletirmos acerca da pobreza multidimensional, contamos com as reflexões de teóricos que há muito já se debruçam sobre essa temática e que, mesmo não utilizando, muitas das vezes, o termo "multidimensional", compreendem a pobreza a partir de múltiplas dimensões, a exemplo de Demo (2003), que trabalha com a pobreza política, de Silva (2009), que apresenta a pobreza refletida a partir da abordagem multidimensionalista, e de Milton Santos (1979), que nos chama a atenção para refletir sobre a pobreza não apenas em sua dimensão econômica, mas também política e social.

Vivemos em uma sociedade marcada pelas desigualdades sociais, que, por um lado, alcança recordes no que tange à produção e tecnificação, mas que, por outro, ainda é incapaz de minimizar a problemática estruturante da pobreza. Embora esteja hoje na pauta das grandes discussões, a compreensão da pobreza ainda costuma estar limitada ao fator renda. Consideramos, não obstante, que a pobreza vai muito além da carência monetária e material, sendo, antes de tudo, ideológica. De acordo com este entendimento, Demo (2003) diz que:

Pobreza não se restringe a carência dada, natural, mas inclui aquela produzida, mantida, cultivada, por conta do confronto subjacente em torno do acesso a vantagens sociais, sempre escassas em sociedade. Ser pobre não é apenas não ter, mas, sobretudo ser impedido de ter, e, sobretudo de ser, o que desvela situação de exclusão injusta (DEMO, 2003, p. 38). 
Nessa linha, podemos destacar que a pobreza não é algo natural, mas imposta, especialmente pelos ditames da ideologia capitalista, tendo em vista que o capitalismo se alimenta frequentemente das disparidades econômicas e sociais, revelando sua face perversa, como considerou Santos (1979), reproduzindo-se de maneira desigual e combinada. Fica nítido, então, que, "a desigualdade é inerente ao sistema capitalista de produção e, portanto, reflete a lógica capitalista" (SILVA, 2009, p. 27).

Mediados por essas reflexões, comungamos com a perspectiva da pobreza a partir da abordagem multidimensional, segundo a qual é necessário refletir sobre esse problema a partir de vários aspectos (pela ótica econômica, política, cultural e social), o que, além de evitar o empobrecimento da reflexão, a enriqueceria. Diagnosticando essa abordagem multidimensional, Silva (2009) considera que

Trata-se de uma dimensão essencialmente social, senão, política da pobreza. Isso porque as condições de vida não se restringem exclusivamente aos aspectos materiais como moradia, alimentação e renda. Elas incluem as relações sociais, acesso ao trabalho, assistência médica, entre outras dimensões (SILVA, 2009, p. 55).

As reflexões de Rego e Pinzani (2013, p. 149) auxiliam nossa discussão ao compreenderem a pobreza numa perspectiva pluridimensional ${ }^{5}$, que considera vários fatores, além da renda, para que se possa dimensionar um sujeito como pobre. De acordo com os autores, a renda não diz tudo sobre o nível de bem-estar dos indivíduos. Num estado, por exemplo, onde o bem-estar social é altamente desenvolvido e os direitos básicos com qualidade são garantidos a todos os cidadãos, "uma baixa renda não significaria uma vida sem confortos", mas, considerando que o Estado não garante os serviços básicos gratuitos e de qualidade, "até uma renda relativamente elevada pode não ser suficiente para proteger os indivíduos de riscos normalmente ligados à pobreza", como o acometimento de doenças, catástrofes naturais, desemprego, dentre outras complicações.

Vale ressaltar que os autores acima destacados - em sua obra "Vozes do Bolsa Família" asseveram que o quantitativo da renda é uma dimensão importante. A sua ausência não é a única responsável pela pobreza, mas ela é responsável por suprir o mais emergencial, que é a fome. Ou seja, em uma sociedade de mercado, é necessário que o indivíduo tenha acesso à renda para poder ao menos matar a fome, do contrário, não poderemos sequer falar em

\footnotetext{
${ }^{5}$ A perspectiva pluridimensional revela pontos de contato consideráveis com a multidimensional, porquanto ambas as linhas assumem que, para se mensurar a pobreza, é preciso levar em consideração uma série de fatores que vão muito além da renda.
} 
cidadania ou dignidade. A esse respeito, abordaremos adiante a importância do PBF como programa de urgência moral que ainda não minimizou as condições de pobreza, mas que vem diminuindo a pobreza extrema, na medida em que tem permitido ao menos o acesso, embora não satisfatório, à alimentação.

\subsection{Pobreza rural: algumas reflexões}

Segundo alguns pesquisadores, dentre os quais podemos citar Mocelin e Filalho (2010), a pobreza rural, em dados absolutos, tende a ser menor do que a pobreza urbana, mas, se levarmos em conta os dados relativos, constatamos que ocorre o inverso, ou seja, que a pobreza rural se torna maior do que a urbana. Nesse sentido, acreditamos que, para falar de pobreza, é preciso considerar as escalas, não as eminentemente cartográficas, mas as escalas geográficas que privilegiem os dados qualitativos territoriais. A respeito da pobreza rural no Brasil, os dados do IBGE (2010) comprovam que o Nordeste é uma das regiões mais afetadas, conforme se verifica na tabela 01 , que aduz a distribuição da população em extrema pobreza numa escala nacional, regional e estadual.

\begin{tabular}{|l|l|l|l|l|l|l|}
\hline $\begin{array}{l}\text { Recorte } \\
\text { Espacial }\end{array}$ & Pop. total & $\begin{array}{l}\text { Pop. } \\
\text { urbana (\%) }\end{array}$ & $\begin{array}{l}\text { Pop. rural } \\
\text { (\%) }\end{array}$ & $\begin{array}{l}\text { Pop.em } \\
\text { extrema } \\
\text { pobreza }\end{array}$ & $\begin{array}{l}\text { Pop. urbana em } \\
\text { extrema } \\
\text { pobreza (\%) }\end{array}$ & $\begin{array}{l}\text { Pop. rural em } \\
\text { extrema } \\
\text { pobreza (\%) }\end{array}$ \\
\hline Brasil & 190.755 .799 & 84,36 & 15,64 & 16.267 .197 & 53,3 & 46,7 \\
\hline Nordeste & 53.081 .950 & 73,1 & 26,9 & 9.609 .803 & 47,5 & 52,5 \\
\hline RN & 3.168 .027 & 77,8 & 22,2 & 405.812 & 53,4 & 46,6 \\
\hline
\end{tabular}

Tabela 01 - Distribuição da população e da população em extrema pobreza no Brasil, Nordeste e no Rio Grande do Norte (2010). Fonte: IBGE/MDS (2010/2011). Elaboração (LIMA, 2014).

De acordo com os dados acima, fica nítida a comprovação de que o Nordeste é uma das regiões mais pobres do país. Para além dos números reveladores que o Instituto traz, essa pobreza se manifesta igualmente no que concerne ao analfabetismo ( $53 \%$ dos analfabetos do país estão na região Nordeste, representando $16,6 \%$ das pessoas com 15 anos ou mais na região), ao desemprego (o Nordeste apresenta uma taxa de 8,0\% de pessoas desocupadas na faixa etária a partir dos 15 anos, o dobro da região Sul, com taxa de desocupação, para esse perfil, de 4,4\%) e à habitação (cerca de 4 milhões de domicílios no Nordeste são considerados precários, o que leva a região a ser compreendida como a mais vulnerável nessa dimensão), dentre outras variáveis que podem ser conferidas na Pesquisa 
Nacional por Amostra de Domicílios (IBGE, 2014), de onde as informações extras (as que foram expostas neste parágrafo e não estavam contidas na tabela 1) foram retiradas.

Em termos de pobreza extrema ${ }^{6}$, os dados do IBGE (2010) mostram-nos que o Nordeste agrega mais da metade da população brasileira nessa condição: são cerca de 9,6 milhões de pessoas de um total nacional de 16.267.197. A partir desses dados, torna-se visível que, mais do que políticas estritamente econômicas, é preciso repensar as condições de vida da população em extrema pobreza e buscar mecanismos que ao menos minimizem essa problemática no intuito de conquistar, ainda que em um futuro distante, o desenvolvimento do Brasil e de suas regiões de forma menos desigual. Para isso, torna-se indispensável analisar os territórios rurais, onde a pobreza tende a ser tão perversa, e intervir neles.

\section{A territorialização das políticas públicas socias de combate à pobreza: o caso do Programa Bolsa Família}

O presente tópico traz algumas reflexões acerca da territorialização das políticas públicas sociais de combate à pobreza, verticalizando a discussão para o Programa Bolsa Família (PBF). Falamos de territorialização dessas políticas porque partiremos do conceito de território entendido como campo de luta e conflito, em que diversos atores (dentre os quais podemos citar o Estado, a Sociedade e as empresas privadas) atuam com intenções diversificadas. Dentro desse cenário, procuraremos entender a territorialização do Programa por meio da percepção de seus beneficiários.

\subsection{O território como elemento primeiro de análise para a territorialização das políticas públicas sociais}

Abordamos geograficamente o conceito de território, compreendido como uma construção social em que estão materializados os interesses e as disputas de classe, bem como a

\footnotetext{
${ }^{6}$ Cabe lembrar, mais uma vez, que o critério adotado para medir a extrema pobreza está somente ligado à renda, para os domicílios com rendimento. Assim, para designar a população como extremamente pobre, ela precisa estar dentro da linha de até $\mathrm{R} \$$ 70,00 per capita. Quanto aos domicílios sem rendimento, os critérios utilizados dizem respeito às condições de moradia.
} 
produção de desigualdades. Nessa visão, portanto, território é um campo de ação pleno de conflitos e tensões de toda sorte (econômica, política e, quiçá precipuamente, social) e no qual se reclama prementemente, ao menos por grande parte dos sujeitos que o compõem, a mediação das políticas públicas e de seus agentes.

É nessa perspectiva que defendemos a necessidade de se realizar uma leitura do território e das territorialidades construídas para que se possa saber, com maior propriedade, de que forma se deve dar o processo de territorialização dessas políticas de intervenção. Julgamos que somente através de um diagnóstico de base territorial se pode trabalhar para que as políticas tenham força efetiva, quando implementadas, no combate ou minoração das problemáticas sociais, sobretudo da pobreza que resulta das desigualdades sociais, maximizadas pelo sistema capitalistas e por suas forças hegemônicas.

Cabe colocar aqui o nosso entendimento sobre o conceito de território baseado em alguns autores. Um dos principais autores a trabalhar com esse conceito foi o geógrafo francês Claude Raffestin, especialmente em sua obra "Por uma Geografia do poder". Nessa obra, Raffestin (1993) traz a ideia de território não como sinônimo de espaço, mas como uma dimensão posterior a ele, sendo entendido como resultado das ações aí executadas por diferentes atores.

Ainda para Raffestin (1993), o território constitui-se por e a partir do poder. Este poder é mediado pelos agentes do território, a exemplo do Estado, empresas, sociedade, dentre outros. Sobre territorialidade, o autor (RAFFESTIN, 2009) assegura que ela é formada quase que exclusivamente pelas relações sociais de produção. Assim: "a territorialidade pode ser definida como um conjunto de relações que se originam num sistema tridimensional sociedade-espaço-tempo" (RAFFESTIN, 1993, p. 160). Ou seja, a territorialidade se faz a partir das materialidades no território, haja vista representar toda a construção social.

Nota-se que o território é revelador de todas as dimensões da vida do homem e é elemento importante de análise quando discutimos a política social, sendo ponto de partida para a elaboração e implementação das políticas de redução das desigualdades, pois "há desigualdades sociais que são, em primeiro lugar, desigualdades socioterritoriais, pois derivam do lugar onde cada qual se encontra" (SANTOS, 2007, p. 32). 
Por meio dessa lógica, podemos afirmar que a formulação e implementação das políticas públicas sociais propiciam a construção de territorialidades de direito, ou seja, a efetivação da cidadania pela qual o indivíduo tenha condições de conduzir minimamente sua vida social e econômica, de ser legitimamente livre para "ir e vir" e não encontre barreiras impostas pela lei de mercado, segundo a qual só circula livremente e vive com dignidade aquele que pode pagar (\$) por esses benefícios. Quando o Estado se ausenta, sobretudo no diagnóstico e implementação das políticas sociais, as camadas mais desprovidas dos elementos básicos à vida (como o acesso à saúde, alimentação adequada, trabalho, lazer) são as que mais sofrem. Com isso, o ciclo da pobreza torna-se mais forte e complexo.

\subsection{Das políticas públicas sociais ao Programa Bolsa Família}

É inegável o papel do Estado como agente das políticas públicas. Contudo, ele não se configura como único agente, mas junta-se a outros, como empresas, instituições, centros de pesquisas, sindicatos, imprensa e a sociedade civil. Assim, as políticas públicas podem se configurar como uma das estratégias de intervenção para minimizar as desigualdades sociais (LINDO, 2011).

No que se refere ao espaço agrário brasileiro, durante muito tempo, as políticas públicas visaram mais ao médio e ao grande produtor rural, trilhando a lógica da agricultura patronal. Contudo, a partir da década de 1990, o Estado passa a propiciar redefinição, implementação e execução de políticas destinadas para a melhoria do espaço agrário, voltando-se também um pouco para o pequeno agricultor, a exemplo da criação do Programa Nacional de Fortalecimento da Agricultura Familiar (Pronaf) ${ }^{7}$. De acordo com Locatel e Hespanhol (2006, p. 06),

Tal redefinição foi impulsionada pelas mudanças que vinham ocorrendo no cenário econômico, social e político do meio rural, resultante da abertura

\footnotetext{
${ }^{7}$ O Pronaf é o Programa Nacional de Fortalecimento da Agricultura Familiar, cujo objetivo principal é financiar projetos individuais ou coletivos, beneficiando os agricultores familiares e assentados da reforma agrária. Parte da responsabilidade pela criação desse programa está na luta travada pelos movimentos sociais e sindicais no país. Foram eles que permitiram a formalização da categoria dos agricultores familiares, os quais passaram a ter acesso a determinadas linhas de crédito como fonte de auxílio para sua produção agrícola, fosse ela voltada ao mercado ou à subsistência da família. Para maiores esclarecimentos acerca do programa, que não é o foco desta pesquisa, visitar Azevedo (2012).
} 
comercial, do desmantelamento das políticas voltadas para o campo e do modelo tecnológico adotado nas últimas décadas.

Podemos afirmar que o Estado Brasileiro tem construído, ao longo da última década, uma governança voltada em alguns momentos para o bem-estar social. O homem do campo e suas particularidades têm se feito presente na agenda governamental, mas ainda é preciso avançar. São muitas famílias que estão à margem do crescimento e desenvolvimento do espaço agrário brasileiro. A agricultura familiar, embora esteja em alta, ao menos nos discursos, ainda não tem sido motor de mudança eficaz na vida das famílias rurais. Isso porque, embora se tenha investido neste setor, esses investimentos esbarram nas questões burocráticas e institucionais. Acreditamos que políticas como incentivo ao crédito e transferências monetárias, como o PBF, podem contribuir para a minimização da pobreza rural e para tornar possível a permanência do homem no campo. Contudo, essas políticas devem ser pensadas de forma conjunta, e não setorizada, como costuma ocorrer no Brasil.

\subsection{A territorialização do Programa Bolsa Família na comunidade Rural Sítio}

\section{Carnaubal: uma análise socioeconômica a partir da percepção dos beneficiários}

Além das políticas públicas específicas que assistem a população do campo, está o PBF, um dos programas de maior abrangência no cenário nacional (territorializado nos espaços urbanos e rurais) e que integra a dinâmica social de grande parte dos agricultores familiares do Sítio Carnaubal. O PBF é regido pela Lei no 10.836 de 9 de Janeiro de 2004 e apresenta-se como um programa de transferência de renda destinado diretamente às famílias em condição de vulnerabilidade, objetivando permitir que elas possam ter seus direitos humanos básicos de alimentação, educação e saúde garantidos, buscando reduzir a fome e a pobreza no território nacional.

Vale ressaltar que o PBF possui uma população alvo que se insere em dois grupos conforme a renda per capita. O primeiro grupo, de família consideradas pobres, é composto por famílias cuja renda mensal per capita esteja entre $R \$ 77,01$ e $R \$ 154,00$, conforme dados de 2015 do Ministério do Desenvolvimento Social (MDS). O segundo grupo, de famílias consideradas extremamente pobres, representam aquelas cuja renda mensal per capita, segundo a mesma fonte supracitada, não ultrapassa os $\mathrm{R} \$ 77,00$. O valor do benefício passa 
por reajustes, os quais se dão à medida que o auxílio se torna defasado em comparação com o salário mínimo e o valor da cesta básica. Em 2004, por exemplo, as famílias do segundo grupo não poderiam ultrapassar uma renda de $\mathrm{R} \$ 60,00$ per capita.

Vale lembrar que, para ser beneficiário do programa, é necessário que a família esteja cadastrada no Cadúnico (Cadastro Único). O responsável pela coleta das informações dadas pela família é o gestor municipal do programa, o que permite uma agilidade maior na obtenção dos dados. Essa facilidade é reflexo da maior interação entre os entes federativos - Município, Estado e União. É preciso também destacar que não são todas as famílias cadastradas que passarão a se beneficiar pelo PBF, pois elas passam por condicionalidades que lhes permitem ou não fazerem parte do universo do programa ${ }^{8}$.

Ressaltamos ainda que o cartão por meio do qual é retirado o repasse financeiro do PBF para as famílias tem sido destinado preferencialmente às mulheres. A transferência de renda confere ao titular uma "autonomia" (ainda que incipiente) financeira, que, como veremos na seção 4 deste trabalho, representa um passo significativo para a emancipação moral dos sujeitos ${ }^{9}$ e, no que toca às mulheres de modo específico, lhes dá meios para um potencial e paulatino processo de reversão da posição marginalizada em que quase sempre se situam no seio familiar, fruto de uma sociedade histórica e sumamente patriarcal.

De acordo com o Censo IBGE (2010), o município de Água Nova registrou uma população de 2.984 habitantes, dos quais estavam cadastrados no Cadúnico, em 2015, 2.474 pessoas, o que corresponde a $82,9 \%$ da população, que representa a porcentagem de pessoas no município que está na faixa de renda de 0 a três salários mínimos. O total de habitantes da zona urbana corresponde a 1.908 habitantes, estando 76,5\% cadastrados no Cadúnico. A população rural é de 1.076 habitantes, com 94,2\% de cadastro no Cadúnico, o que aponta para uma pobreza rural, em termos relativos, maior do que a pobreza urbana no município.

\footnotetext{
${ }^{8}$ As condicionalidades iniciais dizem respeito à renda per capita familiar de acordo com as variáveis pobreza e extrema pobreza. Nos compromissos quanto à educação, os pais devem matricular todas as crianças de 6 a 17 anos, garantindo-Ihes a frequência escolar em $85 \%$. No que tange à saúde, além de outros aspectos, é preciso manter atualizado peso, altura e controle de vacinas a serem tomadas por aqueles que estão recebendo o PBF. Ademais, as gestantes devem participar do pré-natal e de todas as demais medidas de saúde a elas designadas. Para compreender melhor as condicionalidades, verificar o texto de LIMA (2014).

${ }^{9}$ Como nos lembra REGO; PINZANI (2013).
} 
Na comunidade sítio Carnaubal, residem 78 famílias. Estão cadastradas no Cadúnico (fonte de onde retiramos as informações socioeconômicas das famílias beneficiárias) 68 , das quais 50 famílias são beneficiárias do PBF. Portanto, os dados que ora serão apresentados concernem às 50 famílias beneficiárias que residem na comunidade. Buscamos diagnosticar os dados referentes ao domicílio das famílias, critérios de renda, infraestrutura, saneamento e escolarização, dentro da proposta de entender a pobreza do ponto de vista multidimensional.

Com relação ao tipo de moradia, todas as famílias beneficiadas possuem casa própria. Mas vale ressaltar que $80 \%$ dessas casas vêm de programas de governo para a construção de moradias populares, pois as famílias, devido à dependência financeira, não teriam condições de construir suas próprias casas. Neste sentido, os programas habitacionais em conjunto com o PBF a partir da ferramenta do Cadúnico têm diminuído o déficit habitacional das famílias mais pobres. No entanto, a equiparação desse déficit muitas das vezes é fragilizada devido à falta de infraestrutura e saneamento nos locais onde são construídas as casas populares, conforme se pode averiguar nas duas tabelas abaixo, em que os tipos de esgotamento sanitário e de destino do lixo se justapõem à quantidade de domicílios que os utilizam.

\begin{tabular}{|c|c|}
\hline Esgotamento sanitário & Domicílios \\
\hline Fossas sépticas & 36 \\
\hline Fossas rudimentares & 10 \\
\hline Valas a céu aberto & 4 \\
\hline
\end{tabular}

Tabela 2: Tipos de esgotamento sanitário nas residências da comunidade.

\begin{tabular}{|c|c|}
\hline Destino do lixo doméstico & Domicílios \\
\hline Queimá-lo ou enterrá-lo na propriedade & 22 \\
\hline Jogam-no em terreno baldio & 14 \\
\hline Coleta por empresa terceirizada & 14 \\
\hline
\end{tabular}

Tabela 3: Tipos de destino do lixo doméstico nas residências da comunidade.

Nota-se que, dentre as três opções disponíveis na comunidade para o esgotamento sanitário, a maioria dos domicílios (36, o que corresponde a $72 \%$ do total) possui a menos problemática para a saúde e para o meio ambiente locais, que são as fossas sépticas, ao passo que, no tocante ao lixo doméstico, se dá o contrário, isto é, somente a minoria $(14$, ou seja, $28 \%$ do total) tem acesso a alternativa que, longe de ser ideal ${ }^{10}$, é a menos danosa, qual seja, a coleta por empresa terceirizada.

\footnotetext{
${ }^{10}$ Como não há aterro sanitário na região, o lixão, apesar de levar o problema para longe da comunidade, continua agravando e impactando nocivamente o ambiente.
} 
No primeiro caso, o ideal seria uma rede coletora de esgoto que prezasse pela proteção do meio ambiente e pela saúde dos residentes. Sua ausência precariza as moradias e maximiza as condições de pobreza das famílias. Com respeito ao lixo, verificamos uma vez mais a negligência do poder público local que poderia estender para as demais famílias da comunidade o serviço de coleta seletiva semanalmente, o que, ao menos, minimizaria os impactos negativos na saúde pública e na natureza localizadas.

Dando continuidade à caracterização das famílias, optamos por fazer menção, mesmo que de forma superficial, à dimensão educacional por meio do controle de escolaridade, pois "o insucesso na trajetória escolar pode acarretar também menor acesso a direitos básicos, acabando por reproduzir o ciclo de pobreza da geração anterior" (CRAVEIRO; XIMENES, 2013, p. 110). Conforme dados do Cadúnico (2015) do município de Água Nova, em que se considera, para controle do nível de escolaridade, o grau de estudo do titular do cartão, das 50 famílias, ou melhor e a rigor, dos 50 titulares que as representam, apenas 02 (4\% do total) possuem pelo menos nível superior incompleto, tendo a maioria, 20 titulares (40\%), o Ensino Fundamental incompleto. Complementam esses números, 09 titulares com Fundamental completo, 08 analfabetos, 06 com Ensino Médio completo e 05 com Ensino Médio incompleto.

Verificamos que a baixa escolaridade é acentuada nas famílias pobres e extremamente pobres. Embora tenham acontecido avanços na última década no que tange à inserção de pessoas com baixo poder aquisitivo nas universidades e faculdades do país, como diagnosticado em Craveiro e Ximenes (2013), esse acesso ainda é pequeno, pois, de acordo com as análises feitas no Sítio Carnaubal, a população cadastrada que está no Ensino Superior não chega nem a $1 \%$.

Por fim, a última dimensão analisada nesta pesquisa através dos dados do Cadúnico é relativa à renda familiar, ou seja, de onde provém a principal renda da família beneficiada pelo PBF. Ainda consoante Cadúnico de Água Nova (2015), para 21 famílias (42\% do total), é - PBF a principal fonte da receita, seguido pelo trabalho rural e o informal, com 11 e 10 famílias respectivamente, somando outros $42 \%$. As fontes menos expressivas para o ganho familiar são o trabalho autônomo e o serviço público, com 05 e 03 famílias, nessa ordem, cada. 
Esse quadro, além de revelar a grande dependência das famílias ao recurso do governo, também nos permite ver um aspecto interessante, que é a resistência da agricultura familiar, qual verdadeira insígnia do homem do campo e do trabalho rural, mesmo diante dos vários óbices, amiúde contados em seus relatos, que os agricultores têm de enfrentar: a seca, esse grande desafio conjuntural; os continuados embaraços para a obtenção dos recursos advindos do Pronaf $\mathrm{B}^{11}$, especialmente por razões burocráticas; a falta de apoio técnico para gerir, de maneira sustentável, o uso dos recursos recebidos; a falta de maquinários, como tratores, para o corte de terras; os empecilhos para o acesso aos maquinários disponíveis, que ficam sob a responsabilidade da gestão municipal, muitas vezes negligente à causa, dentre outros pontos.

Nessa perspectiva, o benefício do PBF é calculado a partir da renda das famílias e da composição familiar. Não é levado em consideração o território de vida dessas famílias. Quais as suas localidades: moram em áreas centrais, periféricas, urbanas, rurais? Seria muito importante que o repasse da renda pelo programa pudesse ser diferenciado conforme as vulnerabilidades que os diferentes territórios implicam. A seguir, trataremos da territorialização do programa na comunidade em estudo, salientando a necessidade da leitura do território para que o programa, ao ser implementado, garanta a melhoria social dos territórios onde se insere.

\section{A percepção dos beneficiários do Programa Bolsa Família na comunidade rural Sítio Carnaubal}

Nesta seção, trazemos a voz dos beneficiários do PBF para refletir sobre o juízo de valor que fazem do programa. Partimos do pressuposto de que são os beneficiários, sujeitos do programa, que melhor podem falar a seu respeito. O que temos acompanhado na literatura, salvo algumas poucas pesquisas, é a ausência, nas análises feitas, da percepção dos sujeitos

\footnotetext{
${ }^{11}$ Podem concorrer a essa linha de crédito os agricultores familiares que explorem parcela de terra na condição de proprietário, posseiro, arrendatário ou parceiro, além de outras. Sobre esse grupo B, acessar o link: <http://www.mda.gov.br/sitemda/secretaria/saf-creditorural/sobre-o-programa $>$.
} 
sobre as políticas públicas. É evidente o discurso hegemônico ou puramente acadêmico, marginalizando a voz dos sujeitos que podem contribuir para o entendimento mais aproximado dos impactos da implementação das políticas públicas sociais nos territórios. Com relação ao PBF, Rego e Pinzani (2013) apresentam-nos uma rica pesquisa em que privilegiam a voz dos sujeitos do programa, tornando, dessa feita, a análise mais rica. Essa obra serviu-nos de base metodológica no que concerne ao procedimento de entrevista aos beneficiários e também nos instigou a ouvir os sujeitos de nossa pesquisa, buscando darIhes voz.

Dessa forma, das 50 famílias beneficiárias do PBF na comunidade, realizamos entrevista, mediada por questões abertas, com 25 mulheres titulares ${ }^{12}$ dos cartões do PBF, ou seja, os responsáveis por retirar o recurso mensalmente e aplicá-lo, atendendo às necessidades da família. A escolha dos titulares se deu aleatoriamente e as entrevistas foram realizadas nas casas dos próprios beneficiários. Escolheremos, para serem sistematizadas, algumas das questões que foram levantadas junto aos beneficiários.

Nas primeiras indagações, reportamo-nos inicialmente ao fato de, na maioria dos casos, serem as mulheres as responsáveis pelo benefício nas famílias. Entendemos ser este um dos pontos fortes do programa que tem permitido certa autonomia à mulher. Buscando compreender o entendimento das beneficiárias sobre esse aspecto, verificamos que todas, sem exceção, consideram importante o fato de serem elas as administradoras do cartão. Muitas apontaram que os cônjuges não saberiam utilizar de maneira mais adequada o dinheiro, além de que, como muitas das vezes o auxílio é a única renda da família, ter essa responsabilidade torna-as mulheres menos subjugadas aos seus cônjuges. A fala abaixo evidencia esses aspectos.

Eu penso assim, que esse negócio de deixar o cartão com a mulher foi muito bem pensado pelo governo. Porque nós mulheres temos mais cuidado no gasto com o dinheiro. Tipo, não vamos deixar nossos filhos passarem fome para comprar cigarro, bebida, alimentar algum vício, né? Os homens são mais insensíveis nessa história. Eu falo porque aqui em casa quando eu comecei a receber o bolsa família meu marido é quem tirava o dinheiro e, como ele bebe muito, às vezes chegava em casa sem nada. Era muito ruim saber que você tem um dinheiro, mas não pode usar para

\footnotetext{
${ }^{12}$ Cabe destacar que, dos 50 titulares, apenas dois são homens. Não conseguimos, contudo, realizar a entrevista com nenhum deles, pois um estava ausente devido a questões de trabalho e o outro vive em uma situação fragilizada devido ao alcoolismo, o que nos impossibilitou de ouvi-los.
} 
comprar comida, por exemplo. Lá no CRAS, a assistente me explicou que eu tinha que pegar o cartão de volta e assim eu fiz. Nunca mais entreguei a ele. Não deixo meus filhos passarem fome. Eu me sinto importante porque sou eu quem bota comida em casa. Uso o dinheiro do bolsa para comprar comida e trabalho fazendo unha nos finais de semana aqui pelo sítio e tenho umas clientes também na cidade. Isso ajuda a comprar as outras coisas que faltam. Já disse ao homem daqui que não preciso dele. Vivo com ele para fazer um favor (risos) porque tenho pena dele, mas não sou mais besta não, professora (fala de uma beneficiária, trabalho de campo, 2015) $)^{13}$.

Só com essa fala já seria possível fazer várias análises. Ela é carregada de identidade e de conflitos. A senhora acima, vale lembrar, tem o Ensino Médio completo e só parou de estudar porque engravidou. Tem dois filhos com idade entre 8 e 10 anos. Afirmou que, quando eles tiverem um pouco mais de idade, ela voltará aos estudos. É importante salientar esse aspecto da educação, pois percebemos que os beneficiários com maior tempo de escolaridade são mais reconhecedores dos seus direitos e deveres, pois têm um posicionamento mais político, impõem-se e costumam lutar contra as injustiças geradas pela sociedade e pelo sistema vigente. Além disso, a fala reforça a importância de o cartão estar com as mulheres por vários motivos, dentre os quais, pelo cuidado mais coerente com o destino dado à renda para a compra de alimentos, por exemplo. Em consequência disso, a mulher tem ganhado um pouco mais de autonomia nos seus lares ainda tão marcados por práticas da sociedade patriarcal.

Indagamos se as beneficiárias se consideravam pobres e a quem elas atribuíam sua condição de pobreza. Todas responderam que se consideravam pobres sim. A maioria afirmou que sua pobreza era permitida por Deus, pelo destino: "cada um vem com o seu já traçado". Independentemente de a religião ter sido ou não uma das ou a causa primária para esse tipo de discurso de resignação e assujeitamento social, parece-nos inegável que ela integra o modos operandi desse discurso, sustentando-o, na medida em que esse ponto

\footnotetext{
${ }^{13}$ As falas das colaboradoras foram transcritas preservando todas as palavras enunciadas, seus marcadores conversacionais, tais como "viu", "né", e comentários, sempre entre parênteses, sobre aspectos cinésicos das informantes, "(risos)" ou "(olhos mareados)", por exemplo. Não mantivemos, contudo, de modo a gerar uma leitura mais fluida, marcas da estrutura da língua em sua variedade diastrática, mormente nos níveis fonético e morfossintático. Dessa maneira, construções como "nós que vive" ou "esses mesmo" passaram por soluções do tipo "nós que vivemos" ou "esses mesmos". A área dos estudos linguíticos que presta atenção acurada ao tratamento de dados orais é chamada Análise da Conversação, em cujos princípios, embora de forma assaz simplista e não estrita, estão orientadas as decisões referidas nesta nota de rodapé. Para uma visão introdutória sobre esse campo de investigação, ver Dionísio (2009).
} 
de vista é estreitamente dependente da crença/fé que se tem. Outros elementos, porém, como escolaridade, experiências de insucessos e perdas, dentre outras, possivelmente também tenham seu quinhão na assunção desse ponto de vista alienador e gerador de um estatismo social assaz daninho, não só para as famílias que a possuem, mas para toda a comunidade. Desse modo, consideramos que o enfrentamento da pobreza perpassa por outro desafio, que é a falta de consciência político-social acerca das adversidades com que se confrontam diariamente. Esta é, como nos evidenciou Demo (2003), a forma mais perversa da pobreza, a pobreza política.

Em contrapartida, obtivemos respostas mais politizadas a essa indagação a respeito da pobreza. $12 \%$ das entrevistadas responsabilizaram o Estado e a própria sociedade por sua condição de pobreza, colocando que a questão da pobreza resulta da má concentração de renda do país, que gera uma massiva quantidade da população marginalizada. Novamente, os posicionamentos mais politizados vinham das beneficiárias com maior escolaridades. Vejamos a fala a seguir:

Somos pobres porque tem uma classe de gente rica demais que se enriquece por roubar dos pobres. A culpa não é nossa. Se nos derem trabalho, a gente trabalha, mas os ricos que têm muito, cada vez querem mais. Esse dinheiro do Bolsa é só um auxílio mesmo, mas é um direito nosso, porque nós pagamos os impostos. O governo tem muito dinheiro. Esse benefício ainda é pouco para tanto imposto que pagamos (Trabalho de campo, 2015).

De fato, a pobreza não é algo natural, mas resulta também do sistema perverso que é o capitalismo ${ }^{14}$, da abertura demasiada ao grande capital e da negligência do Estado em suprir a sociedade com os bens básicos à vida, que é educação e saúde de qualidade, bem como a prática do lazer, ou ócio. No entanto, para que o pobre saia de sua condição de subjugação, é preciso que ele tenha oportunidade de avançar na construção do conhecimento. $O$ caminho continua sendo a educação. O conhecimento liberta o sujeito das amarras construídas pelas práticas perversas dessa sociedade dividida em classes.

Com relação à importância do PBF, todas as entrevistadas avaliaram positivamente o programa. Muitos foram os aspectos citados para justificar sua importância. Algumas

\footnotetext{
${ }^{14}$ Nas afirmações dessa natureza, respaldamo-nos sempre em Santos (2003), que considera a perversidade do sistema capitalista através da sua mais abrangente fase, que é a globalização. Os seus aspectos perversos estão espalhados pelo mundo, como a pobreza para os excluídos. Recomendamos a leitura da obra citada para maior compreensão da temática segundo a perspectiva em evidência.
} 
colocaram a questão de ser uma renda mensal que ajuda na compra de alimentos, ao passo que outras colocaram que, por ser a única renda certa da família, sem o PBF e com esse longo período de estiagem, estariam passando fome. A fala abaixo sintetiza a importância do programa na percepção de uma das beneficiárias:

Esse programa tem ajudado muito a nós pobres. Principalmente nós que vivemos no "sítio" porque já tem muito tempo que não temos inverno. Não adianta plantar nem criar bicho. A gente só não passa fome por causa do Bolsa Família. Eu sinto que nós pobres fomos vistos pelo governo. Eu lembro da seca de 1993: quase que morríamos de fome. Os programas da emergência eram mais uma humilhação. Hoje a gente não precisa mais se humilhar, não. O Governo já nos ajuda. É pouco sim, mas dá ao menos para matar a fome. Os pobres hoje têm mais direitos neste Brasil. Eu sou prova disso. Moro nessa casa que conquistei no programa do governo. Tenho o bolsa família e meu marido trabalha de servente quando aparece emprego. Eu também ajudo um pouco em casa nas despesas. Eu trabalho fazendo faxina três vezes na semana. Então uso a bolsa para ajudar, né, mas não dá para sobreviver só dela. É preciso correr atrás de mais um pouco. Temos dois filhos. Só quero esses mesmos, porque não é fácil criar. Quero que eles estudem, façam uma faculdade e tenham um futuro melhor. Eu tive que parar meus estudos porque engravidei (Trabalho de campo, 2015).

Percebemos, através das entrevistas, embasado também na fala acima, quanto o PBF é importante no contexto das famílias beneficiadas. Com a renda do PBF, mesmo sendo mínima, as famílias suprem o mais emergencial, que é o acesso à alimentação, e buscam outras fontes de renda através do trabalho formal ou não formal, para suprir as demais necessidades. Além desse aspecto, percebemos que os beneficiários não são acomodados, como costumam ser jugados. Pelo contrário, a maioria das entrevistadas relatou que desenvolvem algum tipo de trabalho para complementar a renda, rompendo o esteriótipo de estarem parasitando o Estado. A esse respeito, Rego e Pinzani (2013) destacam que:

Em muitas sociedades, a pobreza é considerada o resultado de uma falha moral dos indivíduos, ou até de uma culpa por parte dos próprios pobres, culpa em razão da sua preguiça, incompetência, indolência e assim por diante. Em suma, os pobres são definidos como compradores incompetentes e consumidores imprudentes. [...] No caso brasileiro o debate sobre o Bolsa Família é um bom exemplo da repetição histórica do preconceito e da força dos estereótipos. Nos mais variados ambientes sociais os pobres são acusados de preferir viver do dinheiro da bolsa, em vez de trabalhar, de fazer filhos ${ }^{15}$ para ganhar mais dinheiro do Estado, de usar o dinheiro para comprar cachaça etc. (REGO, PINZANI, 2013, p. 224/225).

\footnotetext{
${ }^{15}$ As últimas pesquisas mostram exatamente o contrário, que a taxa de fecundidade entre os pobres tem diminuído significativamente e que um dos motivos é o acesso a métodos anticonceptivos, como a pílula (ALVES; CAVENAGHI, 2013).
} 
Nessa perspectiva, o combate à pobreza, como já frisamos anteriormente, é o combate ao preconceito, à sociedade cada vez mais dividida em classe, é o combate às perversidades do sistema capitalista. Vivemos em uma sociedade alienada, que se informa através de uma mídia reacionária e corrompida. Muitos dos preconceitos com os beneficiários advêm da repetição de discursos midiáticos e reacionários. O combate à pobreza é, assim, o combate à ignorância, à falta de conhecimento.

Outro aspecto que conseguimos depreender das entrevistas é que o PBF pode ser um dos programas responsáveis, na atualidade, pela permanência do homem no campo, pois o êxodo rural continua acontecendo e, em períodos prolongados de seca, ele se torna mais frequente e acentuado. No entanto, com o auxílio desse recurso, temos visto que as famílias encontram meios mais viáveis para permanecer na zona rural, uma vez que o PBF auxilia a família na aquisição de alimentos e mantém uma linha de interação com outros programas voltados ao campo, como o Pronaf e o PAA ${ }^{16}$. Mediante esse aspecto, a fala abaixo nos auxilia a refletir:

\begin{abstract}
Morar aqui é bom, mas tem sido muito difícil porque não temos mais inverno já faz muitos anos. Eu confesso que, se não fosse o dinheiro do Bolsa, já teria ido embora. Porque como aqui não tem trabalho, fica muito difícil de viver. Mas o dinheiro do bolsa ajuda, né? Porque a gente compra o alimento e como moramos no sítio dá pra criar uns bichinhos, como galinhas, o que ajuda também. Eu mesma não sei o que faria se não fosse essa ajuda que recebemos todo mês do governo. Teria que ir embora mesmo. Eu acharia ruim, né, ter que ir embora porque gosto daqui (Fala de uma beneficiária do PBF. Trabalho de campo, 2015).
\end{abstract}

A fala da beneficiária acima comungou com o pensamento da maioria das mulheres entrevistadas e permitiu-nos reforçar a nossa hipótese anterior de que o acesso à renda através do PBF tem propiciado a permanência do homem no campo. Cabe ressaltar que não acreditamos que essa renda seja o suficiente para uma permanência de forma digna, mas supre o mais emergencial, que é a fome.

Indagamos também se a renda do PBF era suficiente para suprir as necessidades básicas da família. Todas as entrevistadas disseram que não, especialmente por os preços dos alimentos e artigos em geral estarem cada vez mais altos. Contudo, destacaram que, de fato, o benefício tem ajudado a garantir a alimentação, "mas só o básico mesmo". Na

\footnotetext{
${ }^{16}$ O PAA - Programa de Aquisição de Alimentos - representa uma das ações do Fome Zero, objetivando garantir o atendimento de populações em situação de segurança alimentar e nutricional, buscando a inclusão social no campo e fortalecendo a agricultura familiar.
} 
sequência dessas respostas, questionamos sobre qual seria o destino dado pelas famílias à renda do PBF. 75\% das entrevistadas destacaram que a utilizam para comprar alimentação, especialmente lanches, frutas e verduras. $10 \%$ disseram que a utilizam para o pagamento das contas de água, luz e gás. Outros $10 \%$ das entrevistadas sinalizaram que utilizam a renda para as despesas escolares dos filhos e as demais, $5 \%$ das entrevistadas, afirmaram que a utilizam para comprar artigos de vestuário e calçados para elas e para os filhos.

Por fim, buscamos entender o que mudou no contexto da família, com o acesso ao PBF. Foram muitas as respostas que nos deram os meios para compreender as reais mudanças sociais provindas da territorialização do PBF. As falas abaixo sintetizam o olhar, a voz e o posicionamento das beneficiárias:

Ah, meninas, mudou muita coisa, viu! Só em a gente não passar mais fome,
já é muito. Também não somos mais ignoradas nas bodegas quando vamos
comprar alguma coisa. Eu lembro que quando não tinha nada, e trabalhava
só lavando roupa para fora, e quando aparecia alguma lavagem, né, muitas
das vezes que ia comprar alguma coisa, o dono da bodega me perguntava
logo como era que eu iria pagar porque eu não tinha um trabalho certo
(olhos mareados). Depois que comecei a receber o Bolsa, nunca mais
passei por isso, porque eles sabem que todo mês nós temos uma coisa
certa. Mesmo a gente sendo honesta, pobre sempre foi muito humilhado.
Olha até isso mudou (risos), e como mudou (Trabalho de campo, 2015).

Mudou bastante. Só em eu não ser mais humilhada pelo homem daqui. Tudo que eu precisava comprar, até uma calcinha, ele alegava. Como o trabalho é pouco, esse dinheiro ajuda muito. Melhorou muito a nossa situação. Hoje posso comprar um lanche para meu filho, uma frutinha, uma coisinha melhor. $\mathrm{O}$ dinheiro é pouco, mas você sabendo gastar e buscando fazer nem que seja uns bicos, dá para ajudar bastante (Trabalho de campo, 2015).

As falas acima nos conduzem à compreensão de que o Programa Bolsa Família tem surtido efeitos positivos no contexto das famílias beneficiadas. Todas as entrevistadas avaliaram positivamente a implementação do Programa. É óbvio que ele não tem exterminado a pobreza, mas tem incidido, sobremaneira, na pobreza extrema, suprindo ao menos a carência alimentar das famílias. Ele também tem gerado efeitos positivos com relação ao ganho de autonomia das mulheres titulares do cartão. Ainda não sabemos em que medida tem sido esse ganho, mas em nossas pesquisas este tem sido sempre um ponto sinalizado pelas beneficiárias. 
Assim, ainda que o PBF não tenha conseguido transformar radicalmente a situação de pobreza em que vivem milhões de brasileiros, possibilitou-Ihes um ganho de autonomia, a busca por maiores liberdades e a possibilidade de sonhar com um futuro melhor, ao menos para os seus filhos. Os repasses aos beneficiários ainda são incipientes, mas são o começo de uma política de distribuição de renda que aos poucos ganha significância no cotidiano de vida dos sujeitos. A esse respeito, lemos a citação abaixo:

Por todas essas razões, a política de combate à fome e o Bolsa Família podem ser vistos como reconhecimento, por parte do Estado, da urgência política e moral na qual vivem essas mulheres e famílias. Não se pode sequer falar seriamente em democracia sem satisfazer tais urgências. Os recursos empenhados ainda são muito pequenos, mas é o início de um processo social novo para os brasileiros, cuja magnitude e destino ainda são de difícil avaliação (REGO; PINZANI, 2013, p. 214).

Embasado nas reflexões dos autores acima e em consonância com a fala das beneficiárias entrevistadas, é inegável que o PBF atua mui frutiferamente na minoração da problemática da pobreza e da fome ainda acentuadas no país, combatendo, desse modo, as desigualdades e a pobreza extrema. No entanto, ainda é preciso avançar muito e atacar o déficit do Estado Brasileiro com a classe pobre (especialmente a que habita as periferias das grandes cidades e o espaço rural brasileiro), sempre tão marginalizada. Quisemos romper a margem e trazer os sujeitos e suas vozes para o lugar que lhes é de direito: o centro, a esquerda, a direita, a margem e o todo. Esperamos que o sujeito do campo possa ser e estar livre, ubíquo cidadão para quem, como dizia o poeta António Machado, não exista caminho (forma, fôrma), mas que faça seu caminho ao andar.

\section{Para não concluir}

Acompanhamos neste trabalho, por meio do depoimento de 25 mulheres beneficiárias titulares do Programa Bolsa Família, alguns dos caminhos pelos quais se foi materializando em discursos, ações e comportamentos - o Programa Bolsa Família na comunidade Sítio Carnaubal. Ao ser territorializado o PBF, o próprio território viu-se transfigurado à medida que as famílias experienciavam transformações em suas realidades diárias: menos assoladas pela pobreza, criavam-se novas possibilidades ou, sendo menos otimista, reduziam-se as 
impossibilidades. Já não era mais tão impossível sobreviver no campo; já não era mais impossível ter um mínimo de dignidade, ter renda, ter acesso ao consumo; já não era mais impossível sorrir; já não era impossível viver. Vidas, sorrisos, consumos ainda não gozam da plenitude latente, não são suficiente nem satisfatoriamente anchos, mas encontram território em que respirar.

A comunidade apresentada tem as características semelhantes a muitas comunidades do semiárido brasileiro. São comunidades carentes, renegadas muitas vezes pelo poder público. Possuem na agricultura familiar um ponto forte de sobrevivência, mas que se encontra fragilizado pela seca e negligência do Estado. O PBF, contudo, traz meios para fortalecê-lo. Ao auxiliar a família na aquisição de alimentos e manter uma linha de interação com outros programas voltados ao campo, a exemplo do Pronaf e do PAA, ele não só é responsável na atualidade pela permanência do homem no campo em Sítio Carnaubal, mas deixa mostras de que pode semear a esperança de um futuro mais frutífero no campo e do campo. Isso é prova de que o PBF foi territorializado na comunidade em estudo, não representando uma mudança no fenômeno da pobreza, do ponto de vista estrutural, mas ao menos suprindo necessidades mais urgentes que permitem a sobrevivência humana.

Após ouvir a percepção das beneficiárias a respeito do PBF, diagnosticamos que a pobreza é mais perversa devido à subjugação do próprio pobre por falta de conhecimento, fato comprovado por boa parte das entrevistadas responsabilizar a sua condição de pobreza ao destino. Por esse ângulo, notamos que as beneficiárias com maior escolaridade se mostraram mais politizadas e responsabilizaram o Estado e a sociedade por sua condição social. Por meio desses mesmos discursos, porém, vemos mulheres que, graças à renda oriunda do PBF, são o oposto: sentem-se emponderadas porque podem ter seus direitos, podem comprar porque o dono da bodega já confia que elas vão pagar, podem administrar seu lar, trabalham e pensam soluções para recriar suas vidas. Esse polo opõe-se à sombra do fatalismo e do entreguismo com que este parágrafo se iniciou. Não teríamos aqui mais provas de que o PBF foi territorializado?

Esses impactos positivos na conjuntura social, não obstante, não dependem apenas do PBF. Há uma série de políticas públicas cuja territorialização tem imprimido outras mudanças transformadoras nas comunidades. E para que a implementação e o gerenciamento de 
quaisquer políticas públicas possam ser mais efetivos no cumprimento de suas metas, é necessário - mote reiterado à exaustão neste artigo - um diagnóstico do território e das diversas territorialidades instituídas. Em outras palavras: para que as políticas públicas e programas sociais tenham êxito, é preciso considerar a conjuntura territorial em que estão inseridos os futuros beneficiários. Além disso, é preciso que os sujeitos beneficiários (seus posicionamentos, percepções, vivências) dos programas e políticas sociais sejam levados em conta para que se chegue o mais próximo possível a um legítimo impacto positivo e transformador na vida desses cidadãos. Isso também deve remeter às questões e aos conflitos que conformam o espaço agrário brasileiro e que estão atrelados à vida desses sujeitos. É preciso que os programas, antes de chegarem neste espaço, tenham em consideração as demandas territoriais aí existentes. A política pública brasileira, nesse sentido, deve deixar de ser meramente institucional e passar a se tornar cada vez mais territorial. Eis a chave do que temos defendido em nossa pesquisa.

Assim, esperamos que mais pesquisadores se interessem pela leitura do território e das territorialidades marcadas pela marginalização dos grupos sociais. Que esses sujeitos tenham garantido o seu direito de voz e que possam ser ouvidos nas pesquisas e por seus representantes políticos, propiciando-se, assim, a conquista de territórios de direitos, marcados pela defesa e permanência da cidadania.

\section{Referências bibliográficas}

ALVES, J. E. D; CAVENAGHI, S. O programa bolsa família e as taxas de fecundidade no Brasil. In: CAMPELLO, M; MERI, C, M. (Orgs). Programa Bolsa Família: uma década de inclusão e cidadania. Brasília: IPEA, 2013, p. 109 124.

CRAVEIRO, C. B. A; XIMENES, D de A. Dez anos do Programa Bolsa Família: desafios e perspectivas para universalização da educação básica no Brasil. In: CAMPELLO,M; MERI, C, M. (Orgs). Programa Bolsa Família: uma década de inclusão e cidadania. Brasília: IPEA, 2013, p. 233 - 246

DEMO, P. Pobreza da pobreza. Petrópolis, RJ: Vozes, 2003.

DIONÍSIO, Ângela Paiva. Análise da conversação. In: MUSSALIM, Fernanda; BENTES, Anna Christina. Introdução à linguística 2: domínios e fronteiras. São Paulo: Cortez, 2009.

IBGE. Instituto Brasileiro de Geografia e Estatística. Censo 2010: cidades. Disponível em <http://www.ibge.gov.br/cidadesat/topwindow.htm?1>. Acesso em: Out. 2015. 
IBGE. Instituto Brasileiro de Geografia e Estatística. Pesquisa nacional por amostra de domicílios: PNAD. Rio de Janeiro: IBGE, 2013.

KHAN, A. S.; SILVA, L. M. R. Capital social das comunidades beneficiadas pelo programa de combate à pobreza rural - PCPR/Projeto São José - PSJ -Estado do Ceará. Revista de economia e sociologia Rural, Brasília, DF, v. 43, n. 1, p. 101-117, 2005.

JÚNIOR, A. B. [Localização do Sítio Carnaubal, Água Nova - RN]. 2017. 1 Desenho técnico ou mapa, color. Escala: 1: 500.00

LIMA, F. E. S; SOARES, L. D. C. A territorialização do programa bolsa família na comunidade Sítio Carnaubal $R N$ : uma análise socioeconômica. Monografia (Especialização em Educação do Campo -Saberes da terra), Instituto Federal de Educação, Ciência e Tecnologia do Rio Grande do Norte, Pau dos Ferros, 2015.

LINDO, P. V. de F. Geografia e política de assistência social: territórios, escalas e representações cartográficas para políticas públicas. São Paulo: Cultura Acadêmica, 2011. Disponível em: <http://www.culturaacademica.com.br/_img/arquivos/Geografia_e_politica_de_assistencia_social.pdf>. Acesso em: Dez. 2012

LOCATEL, C. D.; HESPANHOL, A. N. Mudança de paradigma e a nova concepção de desenvolvimento rural. In: Anais do II Encontro de Grupos de Pesquisa, UFU: Uberlândia.

MOCELIN, C, E; FIALHO, M, A, V. Pobreza rural e bolsa família: análises a partir da comunidade São João do Barro Preto no município de Julho de Castilhos/RS. In: CONGRESSO LATINOAMERICANO DE SOCIOLOGÍA RURAL, 8., 2010, Porto de Galinhas - PE. Anais..., Porto de Galinhas: [s.n.], 2010. Disponível em:< http://www.alasru.org/wp-content/uploads/2011/09/GT27-Cassia-Engres.pdf.> Acesso em: ago. 2015.

RAFFESTIN, C. Por uma Geografia do Poder. França. São Paulo: Ática, 1993.

RAFFESTIN, C. A produção das estruturas territoriais e sua representação. In: SAQUET, M. A; SPOSITO, E. S. (Orgs.). Territórios e territorialidades: teorias, processos e conflitos. São Paulo: Expressão Popular: UNESP. Programa de Pós-Graduação em Geografia, 2009. p. 17 - 35.

REGO, W. L.; PINZANI, A. Vozes do Bolsa Família: autonomia, dinheiro e cidadania. São Paulo: Ed. Unesp, 2013.

ROSSI, R. Uma contribuição geográfica para a problematização da perspectiva territorial nas políticas públicas: Análise espacial a partir do Índice de Desenvolvimento das Famílias em Presidente Prudente - SP. 2012.110 f. Dissertação (Mestrado em Geografia) Faculdade de Ciências e Tecnologia, Universidade Estadual Paulista Júlio de Mesquita Filho, Presidente Prudente - SP.

SANTOS, M. Pobreza urbana. 2ª ed. São Paulo: Hucitec. 1979. (Coleção estudos urbanos).

SANTOS, M. Por uma outra globalização: do pensamento único à consciência universal. 10. ed. Rio de Janeiro: Record, 2003.

SANTOS, M. O espaço do cidadão. 7. ed. São Paulo. Edusp, 2007. (Coleção Milton Santos, vol. 8).

SILVA, A. M. R. da. Um estudo sobre a pobreza multidimensional na Região Nordeste do Brasil - Dissertação (mestrado) - Universidade Federal de Uberlândia. Programa de Pós-Graduação em Economia. Uberlândia/MG, 2009, $192 \mathrm{f}$.

SOARES, S; RIBAS, R. P; SOARES, F.V. Focalização e cobertura do programa Bolsa-Família: qual o significado dos11 milhões de famílias? $2009 . \quad$ Disponível em: <http://www.ipea.gov.br/sites/000/2/publicacoes/tds/td_1396.pdf>. Acesso em: 15 fev. 2011.

SOUZA, I. de; FILHO, M. Os degredados filhos da seca. 3. ed. Petrópolis, RJ: Vozes, 1984. 